\title{
A kinder, gentler age
}

With the Liberal Democrats promising to extend free personal care to all UK elderly people and to let local authorities commission health services, Nick Timmins finds the party's approach has a quite different feel from those of its rivals

Voters contemplating their choice in the run up to the general election on 5 May-and wanting to base that decision on policies for the health servicecould be forgiven if they thought that two different NHSs were being debated in the election campaign.

One battle, between the Conservatives and Labour, looks set to focus on allegations that the extra billions that have been poured into the NHS have been wasted, as well as focusing on waiting lists, access, choice, and, above all, the use of the private sector.

The other, being fought by the Liberal Democrats, has a rather different feel. The party's headline policy is the introduction in England and Wales of the free personal care for elderly people that the Scots already get. This policy would, on the Liberal Democrats' own costings, add more than £1.5bn (\$2.8bn; €2.2bn) to spending next year and around £9bn over the full life of the parliament.

Beyond that, the Liberal Democrats promise to "fight superbugs," reintroduce free eye tests and dental checks, review prescription charges so that fewer people with long term conditions pay them, and put more effort into prevention and early detection-including the development of "health MOTs" (annual checks). Much of the money for that comes from the party's proposal to impose a $50 \%$ tax on incomes above $£ 100000$.

They also have a public health programme that reads a little like Labour's one on speed: an unequivocal rather than qualified promise to ban smoking in all enclosed public places, a "traffic light" system of food labelling, the promotion of walking and cycling, and turning the health department into a department for health rather than a department of health services.

In other words, at first sight the Liberal Democrats' manifesto for health feels like one from a slightly kinder, gentler age. It addresses a broad public health and social care agenda-one that may well appeal to at least some

trench in the battle between the other parties) are missing. Indeed, the line of Charles Kennedy, as Liberal Democrat leader, is that "our campaign will be about providing a quality health service closer to home.

"It will not be about the false 'choice' being promoted by the other main parties," he said.

Paul Burstow, the party's health spokesman, explains that part of the reason for this divergence from the two other main parties is that much of the currently planned machinery would come up for review if the Liberal Democrats form a government.

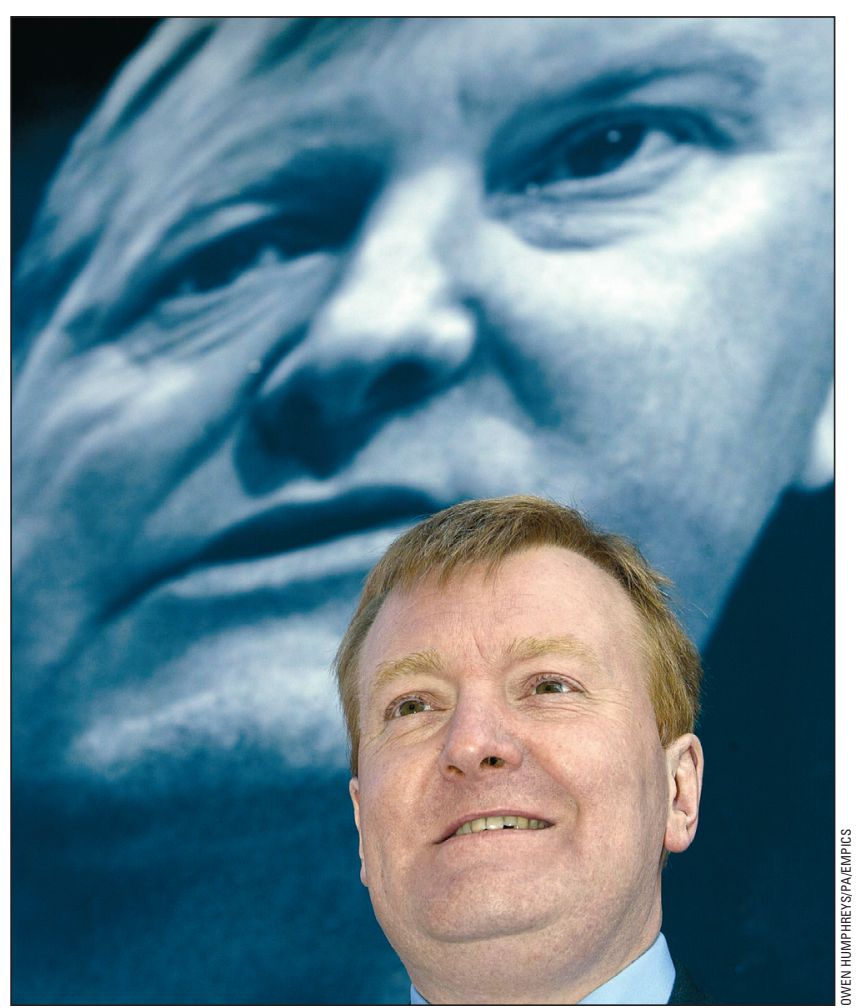

Liberal Democrat leader Charles Kennedy says the campaign "will not be about the false 'choice' being promoted by the other parties"

doctors-rather than engaging in the trench warfare over managerial and financial issues that the other two main parties are currently occupied with and that so affects the lives of clinical staff in the NHS.

It does include the promise made by opposition parties the world over to slash red tape, and (along with the Tories) the Liberal Democrats say they would abolish targets.

But the terms payment by results, foundation trusts, expanded (or indeed diminished) use of the private sector, and even choice (the central
The party, he says, has "serious reservations" about how payment by results will work, believing a real risk exists that the system will focus attention still further on elective treatment at the expense of more chronic conditions.

The Liberal Democrats voted against foundation hospitals and would review them too, although they share the rhetoric of all the major parties that favours more managerial and financial freedom for all hospitals.

The party says it would use the private sector to speed up diagnosis-buying in tests and scans to tackle the "hidden waits" that Labour acknowledges it will have to tackle to hit its target of an 18 week maximum wait from GP to operation by 2008.

But the Liberal Democrats have reservations about using the private sector more broadly. The party is in favour, $\mathrm{Mr}$ Burstow says, where it would clearly add to capacity and is value for money. But it wants "additionality not substitution" and argues that it is crazy to impose use of the private sector to increase competition if the result is that NHS scanners, theatres, or other facilities go unused.

It is equally opposed to the Conservatives' plan for a voucher system for elective care, under which patients would take half the cost of an operation to spend in the private sector.

Because this policy would immediately result in the government having to provide $£ 1$.2bn towards private operations, even before the likely rise in the number of people opting for the private sector, the policy is "deeply unpopular" among voters, Mr Burstow says. "The principle is one that people don't like."

A key reason for the party's relative silence on these issues is that in some ways it has the most radical prescription of all the parties for the organisation of the NHS, even though this gets only a tiny paragraph in its health mini-manifesto. It would move the commissioning of care to local authorities, giving democratic control of the health service to locally elected people, with council consortiums commissioning more complex services.

That would mean the disappearance of central targets, with decisions being made locally about waiting times, use of the private sector, GP commissioning, and much else. It would, Mr Burstow concedes, mean "local variation across the country." But it would, he claims, provide "a much closer fit between need and delivery locally" and a real chance to coordinate better health and social care.

Nicholas Timmins public policy editor, Financial Times

This is the first of three articles on the health policies of Britain's three main political parties, the Liberal Democrats, the Conservatives, and the Labour party, which the $B M J$ will be carrying in the three weeks before the general election on 5 May. 